\title{
Age differences in memory for prospective compared with retrospective subject-performed tasks
}

\author{
BARBARA M. BROOKS and JOHN M. GARDINER \\ City University, London, England
}

\begin{abstract}
In two experiments, younger and older adults studied three lists of verbal phrases, each of the latter describing a simple action. One list was studied and recalled verbally; one was recalled verbally, but the actions were performed at study [retrospective SPTs (subject-performed tasks)]; and one was studied verbally and the actions were performed at test (prospective SPTs). With long lists, but not with short ones, retrospective-SPT recall exceeded verbal recall and older adults recalled fewer SPTs than did younger adults. Prospective-SPT recall did not exceed verbal recall at either list length, and in each of these prospective-SPT tests, older adults recalled fewer action phrases than did younger adults. Thus, it appears that when retrospective and prospective tasks are equated there are marked age differences that are generally consistent with the view that memory impairment in the elderly is more likely to occur in tasks that make higher attentional processing demands.
\end{abstract}

Recent years have seen the development of at least two distinct lines of research on memory for actions. One line of research concerns memory for actions that a person performed in the past. Another concerns memory for actions that a person intends to perform in the future, termed "prospective memory." As the White Queen remarks in Alice Through the Looking Glass, "It's a poor sort of memory that only works backwards."

Memory for actions that a person performed in the past has commonly been studied by presenting subjects with brief verbal phrases, each of which describes a simple action-such as "peel a banana" or "raise your hat." Subjects either perform the actions at study-a condition referred to as "subject-performed tasks" (SPTs)-or learn the phrases verbally. They then take a verbal recall test.

Recall of SPTs is often (though not always) superior to verbal recall and seems to differ from verbal recall in a number of other ways (see, e.g., Cohen, 1981, 1983). For example, recall of SPTs shows no primacy effects. It has been suggested that SPTs are encoded more automatically or in a more elaborative form, with multimodal components that include visual and motor components (for a brief review, see Nilsson \& Craik, 1990).

We are grateful to Lars-Goran Nilsson for providing us with translations of the action phrases used in his studies. In addition, we thank members of the University of the Third Age for their cooperation. Barbara Brooks is now at the Department of Psychology, Goldsmiths' College, University of London, New Cross, London SE14 6NW. Correspondence on this article should be addressed to John Gardiner, Department of Psychology, City University, Northampton Square, London EC1V OHB, U.K.

-Accepted by previous editor, Margaret Jean Intons-Peterson
Memory for actions that a person intends to perform at some future time has been studied using a variety of tasks both in the laboratory and in the natural environment (for a review, see Morris, 1992). In the laboratory these tasks have included pressing a particular key (Schonfield \& Shooter, reported by Welford, 1958) and changing pens at some later point in the procedure (Dobbs \& Rule, 1987). In the natural environment these tasks have included keeping a diary, making a telephone call, and mailing a card with a particular message (Moscovitch, 1982; Poon \& Schaffer, 1982; West, 1984). All these tasks, too, might equally well be termed SPTs, although in these studies, unlike traditional SPT research, subjects have typically been required to remember to perform only one task, or at most a few, and to remember to do so at a particular time without being further prompted by the experimenter. Unlike previous research, our concern is mainly with memory for what the actions are rather than for the time at which they have to be performed.

There has been relatively little research on memory for tasks to be performed in the future and, until the present study, there had been none in which a direct comparison has been made between what we shall call memory for prospective SPTs and memory for retrospective SPTs. One major aim of the present article is to report the results of such a comparison. A key feature of this comparison, of course, is that the same tasks are used in prospective and retrospective performance conditions. In previous studies, prospective and retrospective memory tasks have been different (e.g., Einstein \& McDaniel, 1990; Kvavilashvili, 1987; Maylor, 1990; Wilkins \& Baddeley, 1978).

In making this comparison we took a lead from a procedure developed by Koriat, Ben-Zur, and Nussbaum 
(1990) for studying what we refer to as prospective SPTs. Koriat et al. had subjects study action phrases for either a verbal recall test or a test in which the actions had to be performed. Across a variety of conditions in each of three experiments, Koriat et al. found that subjects actually recalled more of the actions when they had to perform them in the test. Koriat et al.'s third experiment deliberately paralleled the procedure used in retrospective SPT research in that it had a larger, more varied set of tasks and a longer retention interval. In discussion, Koriat et al. suggested that there may be similarities between the effect they obtained and retrospective-SPT recall: Both phenomena might reflect similar representational propertieselaborative properties that involve visual and motor components. On the other hand, Koriat et al. found that there were primacy effects in their performance condition, effects that are not found in retrospective-SPT recall. This suggests that memory for prospective tasks is less automatic and more effortful than memory for retrospective tasks.

A second major aim of the present article was to report further evidence on these issues provided by a comparison of how well younger and older adults did in both retrospective- and prospective-SPT recall.

With respect to both retrospective and prospective tasks, evidence from previous studies of age differences is equivocal. Earlier studies of retrospective SPTs showed that age differences were greatly attenuated (Backman \& Nilsson, 1984, 1985), but more recent studies have found age differences in retrospective-SPT recall similar to those obtained following verbal-study conditions (Cohen, Sandler, \& Schroeder, 1987; Nilsson \& Craik, 1990).

Craik and Jennings (1992) point out that further work is obviously needed to resolve this discrepancy. They also suggest that neither presentation rate nor list length is likely to be the differentiating variable, because the different outcomes have been obtained with the same presentation rate, and the same outcomes have been obtained with short and long lists. The evidence concerning possible list-length effects, however, is not strong. In one study, the comparison between long and short lists was made between experiments-experiments that differed with respect to various other conditions, too (Nilsson \& Craik, 1990). In the other case, where the list-length comparison was made within one experiment, there was at least a tendency for age differences in SPT recall to be attenuated with short lists (see Cohen et al., 1987, Figure 3).

Nor is the evidence from previous studies of actions to be performed in the future any less equivocal. Some studies have found no age-related memory decrement in such tasks (Cockburn \& Smith, 1988; Einstein \& McDaniel, 1990; West, 1988). In other studies, or other conditions of the same studies, it has been found that older adults do less well than younger adults (Cockburn \& Smith, 1988; Dobbs \& Rule, 1987; West, 1988). What any differentiating variable might be in such studies is even less clear, not least because of the greater variety of tasks used and because, in studies carried out in the natural environment, many variables remain uncontrolled.

Craik's $(1983,1986)$ theory of age-related decrements in memory is that they are most likely to occur under more demanding task conditions, conditions that provide little or no "environmental support" at either encoding or retrieval. That is, age differences are most likely to occur when encoding or retrieval tasks "require self-initiated constructive operations" - operations that require more attention and effort (Craik, 1983, p. 350). Essentially, older people carry out such self-initiated processing less efficiently. As Einstein and McDaniel (1990) argued, according to this theory one would expect marked age differences in prospective SPTs. In contrast, retrospective SPTs provide very strong environmental support at encoding, including activation of the motor system (Engelkamp \& Zimmer, 1985). Older adults may sometimes benefit disproportionately from this support because younger adults are more adept at spontaneously initiating the richer, more elaborative encoding that these SPTs provide automatically (see Craik \& Jennings, 1992). Thus, Craik's theory predicts that, other things being equal, age differences are more likely with prospective SPTs than with retrospective SPTs. Moreover, this theory further predicts that age differences within retrospective-SPT recall should also increase if the task is made more demanding in other ways.

Alternatively, taking the view that both prospective and retrospective SPTs share similar underlying representational properties (Koriat et al., 1990), one could predict that there might be parallel effects of age in the two kinds of task.

\section{EXPERIMENT 1}

In this experiment, younger and older adults studied three lists of 15 action phrases. One list was studied verbally for a verbal recall test; one was studied verbally for subjects to perform the actions at test (prospective SPTs); and one was recalled verbally after subjects had performed the actions at study (retrospective SPTs).

The action phrases were based on those used in previous similar studies (Backman \& Nilsson, 1984; Koriat et al. 1990; Nilsson \& Craik, 1990), except that all of them involved an imaginary object. In previous studies the actions have usually been more varied, sometimes also involving real objects or no object. We used only actions involving imaginary objects because Koriat et al. reported that these were the actions that produced the largest advantage in prospective SPTs.

\footnotetext{
Method

Subjects. Two groups of 18 volunteer subjects each participated in the experiment. One group consisted of 8 female and 10 male undergraduate students from City University, London, with an age range of 18-32 years and a mean age of 20 years. The other group was composed of 11 female and 7 male older adults, most of whom were members of the University of the Third Age, with an age range
} 
of 60-83 years and a mean age of 69 years. All subjects were community dwelling and non-institutionalized. They were tested individually and were paid for their participation in the experiment, which lasted approximately 30 minutes. Older subjects performed significantly better than younger subjects on a shortened version of the Mill Hill Vocabulary Test [mean scores 17.17 vs. 13.89, $t(34)=4.56, p<.001]$. Younger subjects had more years of fulltime education than older subjects, but the difference was not significant [mean years 13.89 vs. $12.86, t(34)=1.42, p>.10$ ].

Design and Materials. The factors were age (younger vs. older adults) and task (retrospective-SPT vs. prospective-SPT vs. verbalcontrol tasks). Task was a within-subject factor, with the three tasks counterbalanced for order across subjects within each age group.

Stimulus material comprised 60 cards, each typed with an action phrase involving an imaginary object-for example, "fly a kite," "beat an egg," "pump up a bicycle tyre." (A full list of these action phrases is available on request.) Fifteen cards were set aside to be used as practice cards; the remaining 45 were randomly allocated to three equal sets. During the experiment, six different random allocations of these 45 cards were used and each allocation was counterbalanced across the three tasks.

Procedure. Subjects were tested individually. They initially read an explanatory note describing the procedure. Before each critical study phase, the subjects were presented and tested with five action phrases for practice with each particular study and test procedure to ensure that they knew in advance exactly what the study and test conditions were. During each critical study phase, the subjects heard the experimenter read aloud 15 action phrases at sixsecond intervals. There followed a short oral instruction appropriate for the test. In the retrospective-SPT condition, the subjects performed the tasks after each phrase was presented. They then recalled orally any tasks they remembered. In the prospective-SPT condition, the subjects listened to the phrases anticipating that they would be required to perform the tasks. They then performed any tasks they remembered. In the verbal-control condition, subjects listened to the phrases and recalled orally any they remembered. For each test, subjects were allowed about two minutes for recall. When all three tests had been completed, subjects spent 10 minutes performing a shortened version of the Mill Hill Vocabulary Test.

A lenient scoring procedure was used for prospective SPTs. If a task could be clearly recognized it was allowed. On two occasions, a subject's performance proved impenetrable and he or she was asked to name the task

\section{Results and Discussion}

The principal results of the experiment are summarized in Figure 1. The main features of these results are readily apparent. Younger adults' memory performance was similar for all three lists, although there was a tendency for recall of retrospective-SPT lists to exceed recall of the other two. In contrast, older adults were markedly impaired in their recall of both prospective-SPT lists and verbal-control lists, but recalled considerably more from retrospective-SPT lists, so that for the latter, age differences were essentially absent.

Statistical analyses of variance (ANOVAs) support the foregoing description of the data. In these analyses, the alpha level was set at .05 throughout. Since preliminary analyses showed no significant effect of order and no significant interaction between order and task or age, data were collapsed across this variable. ${ }^{1}$ A $2 \times 3$ ANOVA was then performed with the factors age and task. There was a significant main effect of age $\left[F(1,34)=13.39, M S_{e}\right.$ $=4.21]$ and of task $\left[F(2,68)=12.69, M S_{e}=2.62\right]$, and

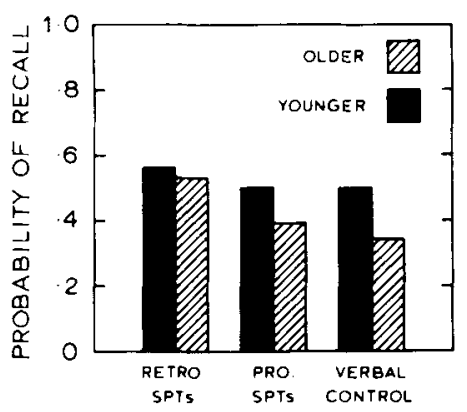

Figure 1. Probability of task recall as a function of age.

the interaction between task and age was also significant $\left[F(2,68)=3.70, M S_{\mathrm{e}}=2.62\right]$.

Tukey $H S D$ comparisons, performed to trace the source of the above interaction, showed that age was not significant in retrospective-SPT recall $(p=.993)$, that it approached significance in prospective-SPT recall ( $p=$ $.079)$, and that it was significant in verbal-control recall $(p=.002)$.

Separate ANOVAs were performed to investigate differences between the three tasks within each age group. No significant difference between the three tasks was found for younger subjects $\left[F(2,34)=1.18, M S_{\mathrm{e}}=\right.$ 3.32], but there was a significant difference for older subjects $\left[F(2,34)=20.32, M S_{\mathrm{e}}=1.92\right]$.

Tukey $H S D$ comparisons performed on older subjects' scores showed significant differences between retrospectiveSPT and verbal-control recall $(p<.001)$, and between retrospective- and prospective-SPT recall $(p=.003)$, but not between prospective-SPT and verbal-control recall $(p=.77)$.

The serial position data for the three tests were recorded. To reduce noise, these data were combined over each three consecutive serial positions. These data are summarized in Table 1. The important issue concerning these data is whether there are primacy effects in prospective SPTs (Koriat et al., 1990) and not in retrospective SPTs (Cohen, 1981, 1983). The presence of primacy effects was assessed by comparing probabilities of recall for serial positions 1-3 with probabilities of recall for serial positions $7-9$. Separate $2 \times 2$ ANOVAs were performed for each of the three tests, with serial position as the first factor and age as the second factor. There was no significant effect of serial position in retrospective-SPT recall $\left[F(1,34)=1.44, M S_{\mathrm{e}}=0.62\right]$. There were significant effects of serial position both in prospective-SPT recall $\left[F(1,34)=13.63, M S_{\mathrm{e}}=0.74\right]$ and in the verbalcontrol condition $\left[F(1,34)=11.52, M S_{\mathrm{e}}=0.69\right]$. The only other significant effects in these analyses were main effects of age both in prospective-SPT recall $[F(1,34)=$ $\left.6.78, M S_{\mathrm{e}}=0.74\right]$ and in the verbal-control condition $\left[F(1,34)=11.52, M S_{\mathrm{c}}=0.69\right]$.

Thus, the results of this experiment show some similarities and some differences compared with those obtained 
Table 1

Probability of Recall as a Function of Serial Position, Age, and Task in Experiment 1

\begin{tabular}{llllll}
\hline & \multicolumn{5}{c}{ Serial Positions } \\
\cline { 2 - 6 } \multicolumn{1}{c}{ Age/Task } & $1-3$ & $4-6$ & $7-9$ & $10-12$ & $13-15$ \\
\hline Younger Adults & & & & & \\
Retrospective SPT & .51 & .60 & .62 & .67 & .93 \\
Prospective SPT & .80 & .69 & .47 & .47 & .56 \\
$\quad$ Verbal & .82 & .51 & .44 & .44 & .80 \\
Older Adults & & & & & \\
Retrospective SPT & .62 & .44 & .69 & .62 & .80 \\
Prospective SPT & .56 & .47 & .29 & .42 & .62 \\
$\quad$ Verbal & .49 & .36 & .33 & .35 & .53 \\
\hline
\end{tabular}

in previous studies. Most surprising, perhaps, is the failure to replicate Koriat et al.'s (1990) effect of superior recall of prospective SPTs compared with the verbal-control condition. No obvious reason for this difference is apparent, particularly given that our experiment was closely modeled on Koriat et al.'s third experiment and used the kind of actions that, in their experiment, produced the largest effect. On the other hand, our experiment did replicate their finding of primacy effects in this prospective task.

Other studies than ours have found little difference in younger adults' recall of retrospective-SPT lists and verbalcontrol lists (Backman \& Nilsson, 1984, 1985). In these studies list lengths have been short. With short lists, it is quite likely that sometimes younger adults spontaneously initiate rich, elaborative encoding strategies that offset any possible benefits from encoding these SPTs. Older adults are less likely to be able to do this and so benefit more from the environmentally driven encoding that these retrospective SPTs automatically provide (Craik, 1983, 1986).

More broadly, insofar as list length affects general task difficulty, it is possible that this factor is sometimes implicated in determining both the circumstances in which younger adults show superior recall of retrospective SPTs and the circumstances in which older adults benefit disproportionately from such tasks. As we mentioned in the introduction, evidence concerning this possibility is sparse, but data reported by Cohen et al. (1987, Figure 3) are at least suggestive of it. Experiment 2 was designed to provide further evidence.

\section{EXPERIMENT 2}

Essentially, Experiment 2 was a replication of Experiment 1 with the added factor of list length. Younger and older adults received the same three study-test conditions as before, but for lists both of 12 action phrases (slightly shorter but fairly similar to list length in Experiment 1) and of 24 action phrases.

\section{Method}

Subjects. Two groups of 18 volunteer subjects each participated in the experiment. One group consisted of 11 female and 7 male students from City University, London, with an age range of 18-34 years and a mean age of 25 years. The other group comprised 11 female and 7 male older adults, most of whom were members of the University of the Third Age, with an age range of 60-78 years and a mean age of 68 years. All subjects were community dwelling and non-institutionalized. They were tested individually and were paid for their participation in the experiment, which lasted approximately 30 minutes. Older subjects performed significantly better than younger subjects on a shortened version of the Mill Hill Vocabulary Test [mean scores 10.72 vs. $14.83, t(34)=2.63, p<.025$ ] Younger subjects had spent longer than older subjects in full-time education [mean years 16.33 vs. $11.89, t(34)=4.49, p<.001$ ]

Design and Materials. The factors were age (younger vs. older adults), task (retrospective-SPT vs. prospective-SPT vs. verbalcontrol tasks), and list length (short vs. long lists). Task and list length were within-subject factors, with the six conditions counterbalanced for order across subjects within each age group.

Stimulus material comprised 117 cards, each typed with a different action phrase. Nine cards were used as practice cards. The remaining 108 cards were randomly allocated to three sets of 12 cards and three sets of 24 cards. As in Experiment 1, six different random allocations of these cards were used, with each allocation counterbalanced across the three tasks.

Procedure. The procedure was similar to that of Experiment 1, except that each subject had six lists-two for each task, one a short list and the other a long list.

\section{Results and Discussion}

The principal results of this experiment are summarized in Figure 2, from which it is apparent that, for the short lists, these results are similar to those of Experiment 1. The younger adults' memory performance was similar for all three lists, although there was a slight tendency toward lower recall of prospective-SPT lists. The older adults were again markedly impaired in their recall both of prospectiveSPT lists and of verbal-control lists, but recalled disproportionately more from retrospective-SPT lists. With the long lists, a different pattern of data emerged. Both younger and older adults benefited to a similar extent from retrospective SPTs, compared with the verbal controls; and similar age differences are apparent for all three tasks. Finally, it is obvious once again that the experiment did not replicate the superior recall of prospective SPTs reported by Koriat et al. (1990).

Statistical analyses support the foregoing description of the data. Since preliminary analyses showed no significant effect of task order and no significant interaction involving task order, data were collapsed across this vari-

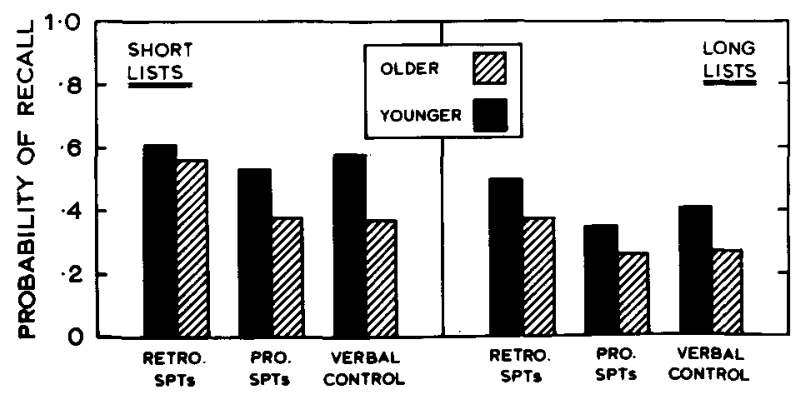

Figure 2. Probability of task recall as a function of age and list length. 
able. ${ }^{2}$ A $2 \times 2 \times 3$ ANOVA was then performed with the factors age, list length, and task. There were significant main effects of age $\left[F(1,34)=24.82, M S_{\mathrm{e}}=0.04\right]$, list length $\left[F(1,34)=95.08, M S_{\mathrm{e}}=0.01\right]$, and task $[F(2,68)$ $\left.=31.37, M S_{\mathrm{e}}=0.01\right]$. There was a significant interaction between task and age $\left[F(2,68)=3.21, M S_{c}=0.01\right]$, but not between list length and age $[F(1,34)<1]$ or between list length and task $[F(2,68)<1]$. The overall interaction between age, list length, and task was significant $[F(2,68)$ $\left.=4.17, M S_{e}=0.01\right]$.

Tukey $H S D$ comparisons were performed between the three short lists and between the three long lists to trace the source of the interaction between test and age. Between the three short lists, the effect of age was not significant for retrospective-SPT recall $(p=.854)$, but it was significant for prospective-SPT recall ( $p=.013$ ) and for verbalcontrol recall $(p<.001)$. Between the three long lists, the effect of age was significant for retrospective-SPT recall $(p=.006)$, approached significance for prospective SPT recall $(p=.076)$, and was significant for verbalcontrol recall $(p=.002)$.

Separate ANOVAs were performed to investigate differences between the six lists within each age group. For younger subjects, there were significant effects of list length $\left[F(1,17)=87.29, M S_{\mathrm{e}}=0.01\right]$ and task $[F(2,34)$ $\left.=10.7, M S_{e}=0.01\right]$, and the interaction between list length and task just reached significance $[F(2,34)=3.26$, $\left.M S_{\mathrm{e}}=0.01\right]$. For older subjects, there were also significant effects of list length $\left[F(1,17)=29.8, M S_{\mathrm{e}}=0.02\right]$ and task $\left[F(2,34)=23.53, M S_{\mathrm{e}}=0.01\right]$, but the interaction between list length and task was not significant $\left[F(2,34)=1.82, M S_{\mathrm{e}}=0.11\right]$.

Tukey HSD comparisons performed on younger subjects' scores showed no significant differences in recall between the three short lists. For the three long lists, there were significant differences between retrospective- and prospectiveSPT recall $(p=.001)$ and between retrospective-SPT and verbal-control recall $(p=.038)$, but not between prospective-SPT and verbal-control recall $(p=.354)$.

Tukey $H S D$ comparisons performed on older subjects' scores showed significant differences for the short lists between retrospective- and prospective-SPT recall ( $p=$ .002 ) and between retrospective-SPT and verbal-control recall $(p=.001)$, but not between prospective-SPT and verbal-control recall $(p=.926)$. For the three long lists, there were significant differences between retrospectiveand prospective-SPT recall $(p=.001)$ and between retrospective-SPT and verbal-control recall $(p=.004)$, but not between prospective-SPT and verbal-control recall $(p=.950)$.

Serial-position data were also recorded in this experiment, but it is not worth reporting these in any detail because they add little of any importance to the serialposition data summarized in Table 1. In Experiment 2, as well, whereas there were primacy effects in prospective SPTs, there were no such effects in retrospective SPTs.

\section{GENERAL DISCUSSION}

The two experiments reported here provide a direct comparison between memory for retrospective and prospective SPTs in younger and older adults. In addition, general task difficulty was manipulated by comparing short with long lists. There were two main findings. First, it was found that both age differences in retrospective-SPT recall and the superior recall of these SPTs depended on list length. With short lists, older adults recalled about as many retrospective SPTs as did younger adults and, unlike the older adults, younger adults recalled about as many of these SPTs as they did the equivalent verbal phrases. With long lists, both younger and older adults showed superior recall of retrospective SPTs compared with their recall of the equivalent verbal phrases, and these SPT effects were similar for each age group. In addition, older adults showed a similar decrement across all three tasks. Second, it was found that there was little difference between the recall of prospective SPTs and that of the equivalent verbal phrases in either younger or older adults. We discuss each of these findings in turn.

The first of these findings is consistent with the idea that with short lists younger adults have little difficulty in spontaneously engaging in rich, elaborative encoding strategies that largely offset the encoding benefits that retrospective SPTs provide automatically. For younger adults, these benefits emerge with longer lists, which demand much more effortful processing.

Older adults, however, have fewer attentional resources than younger adults (Craik \& Byrd, 1982) and are less capable, even with short lists, of spontaneously being able to encode in a rich, elaborative fashion. In these circumstances, older adults show superior recall of retrospective SPTs, and their recall of these lists is similar to that of younger adults. With long lists, where task demands are high, both younger and older adults show similar retrospective-SPT effects.

These findings are clearly consistent with Craik's (1983, 1986) theory of age-related impairments in memory, and they go some way toward resolving the apparent discrepancy between earlier and more recent studies of age differences in retrospective-SPT recall (Craik \& Jennings, 1992). Moreover, the only previous study in which list length was manipulated within one experiment found similar results. Cohen et al. (1987) found significant age differences in SPT recall with long lists but not with short lists. In that study, however, unlike ours, younger as well as older adults benefited from retrospective-SPT recall even with short lists, which suggests that other factors may contribute to and interact with these list-length effects.

Our second main finding was that there was no evidence of the superior memory that Koriat et al. (1990) had found for prospective SPTs compared with the equivalent verbal phrases. The failure to replicate this effect is particu- 
larly puzzling because the SPT conditions in our experiments were closely modeled on the conditions used in their third experiment and we deliberately chose the kinds of actions that Koriat et al. found gave rise to the largest effect-namely, those involving imaginary objects.

Clearly, replicability per se is not in question. Koriat et al. (1990) replicated their effect across a variety of conditions in each of three experiments. Similarly, across all conditions of our two experiments there are no less than six replications of the critical contrast. The evidence therefore points to some as-yet-unknown boundary conditions which limit the generality of the effect. It will obviously require additional research to resolve this issue.

While it seems unlikely, for the reasons we have already discussed, that differences in the nature of the actions used can be the crucial factor, it is possible that differences in the subject populations might be. Koriat et al. (1990) suggested that their effect might reflect greater visual and motoric encoding when subjects anticipate having to perform the actions rather than merely recall verbal phrases. Maybe students in Haifa show more initiative in this respect than students in London; it would not be the first time, even with respect to our own laboratory, that differences between results found by different researchers have turned out to be due to differences in the nature of the subjects (see Gardiner, Gregg, \& Hampton, 1988; Nairne, Pusen, \& Widner, 1985; Nairne \& Widner, 1988).

Be that as it may, our experiments provide evidence of several dissociations between memory for prospective and retrospective SPTs. These dissociations involve agerelated effects, list-length effects, and primacy effects. In general, memory for prospective SPTs was shown to be similar to verbal recall of the action phrases. It was retrospective-SPT recall that proved the odd one out. Thus, our evidence weakens the case for supposing that memory for actions is fundamentally similar in retrospective and prospective tasks.

The terms "retrospective" and "prospective" have been used here strictly to refer to tasks (or task performance). Specifically, they refer to whether, at the end of the study period, the subject has already performed the actions or intends to perform the actions in the forthcoming test. For several reasons, we have avoided the terms "retrospective memory" and "prospective memory."

One reason is that the latter terms have been used in the literature to refer to different forms of memory as well as to different memory tasks. Morris (1992), for example, discussed prospective memory both as a memory system and as a type of task. Gardiner and Java (1993) have argued that memory theory needs to reform its use of terminology so as to avoid such confounding of terms (see also Roediger \& McDermott, in press).

The terms retrospective memory and prospective memory are confusing for another reason, reminiscent of the White Queen's discourse on memory in Alice Through the Looking Glass. Memory is inherently both retrospective and prospective; it always works both backwards and forwards in time. Consider the three main conditions in the present experiments. In all three conditions, recall performance is retrospective in relation to the verbal phrases presented at study and prospective in relation to the test and the subject's intentions to perform that test. Thus even to label these conditions as either retrospective or prospective memory would be misleading; it is the actions that are retrospective or prospective, depending on whether they were performed at study or were intended to be performed at test.

The intention to perform the actions at test must depend on memory for the verbal phrases, and our data, unlike the data obtained by Koriat et al. (1990), revealed no functional differences between this prospective-SPT condition and the verbal-recall control condition. As we pointed out in the introduction, this prospective-SPT condition differs in several ways from the conditions that have usually been investigated under the rubric of "prospective memory." Theoretical claims that memory for actions that a person intends to perform in the future is a different form of memory to that observed in standard laboratory tests, such as free recall, have typically confounded the prospective versus retrospective comparison with gross differences in the nature of the tasks. The prospective-SPT condition as used in the present studies, when combined with the retrospective-SPT and verbalcontrol conditions, does at least allow such comparisons to be made in a relatively unconfounded way. And under these unconfounded conditions, there is little evidence that memory for future actions-at least in terms of what the actions are, if not in terms of the time at which they have to be performed-differs much from what used to be called verbal memory.

\section{REFERENCES}

Backman, L., \& NiLsson, L.-G. (1984). Aging effects in free recall: An exception to the rule. Human Learning, 3, 53-69.

Backman, L., \& Nilsson, L.-G. (1985). Prerequisites for lack of age differences in memory performance. Experimental Aging Research, 11, 67-73.

CoCKBURN, J., \& SMITH, P. T. (1988). Effects of age and intelligence on everyday memory tasks. In M. M. Gruneberg, P. E. Morris, \& R. N. Sykes (Eds.), Practical aspects of memory: Current research and issues (Vol. 2, pp. 132-136). Chichester, U.K.: Wiley.

Cohen, R. L. (1981). On the generality of some memory laws. Scandinavian Journal of Psychology, 22, 267-281.

CoHEn, R. L. (1983). The effect of encoding variables on the free recall of words and action events. Memory \& Cognition, 11, 575-582.

Cohen, R. L., SANdler, S. P., \& Schroeder, K. (1987). Aging and memory for words and action events: Effects of item repetition and list length. Psychology \& Aging, 2, 280-285.

CRaIK, F. I. M. (1983). On the transfer of information from temporary to permanent memory. Philosophical Transactions of the Royal Society of London, Series B, 302, 341-359.

CraIK, F. I. M. (1986). A functional account of age differences in memory. In F. Klix \& H. Hagendorf (Eds.), Human memory and cognitive capabilities, mechanisms and performances (pp. 409-422). Amsterdam: Elsevier North-Holland.

Craik, F. I. M., \& BYrD, M. (1982). Aging and cognitive deficits: The role of attentional resources. In F. I. M. Craik \& S. Trehub (Eds.), Aging and cognitive processes (pp. 191-211). New York: Plenum. Craik, F. I. M., \& JenNings, J. M. (1992). Human memory. In F. I. M. 
Craik \& T. A. Salthouse (Eds.), Handbook of aging and cognition. Hillsdale, NJ: Erlbaum.

Dores, A. R., \&ule, B. G. (1987). Prospective memory and selfreports of memory abilities in older adults. Canadian Journal of Psychology, 41, 209-222.

Einstein, G. O., MCDaniel, M. A. (1990). Normal aging and prospective memory. Journal of Experimental Psychology: Learning. Memory, \& Cognition, 16, 717-726.

ENGelkamp, J., \& Zimmer, H. D. (1985). Motor programs and their relation to semantic memory. The German Journal of Psychology, 9, 239-254.

Gardiner, J. M., Gregg, V. H., \& Hampton, J. A. (1988). Word frequency and generation effects. Journal of Experimental Psychology: Learning, Memory, \& Cognition, 14, 687-693.

GARDINER, J. M., \& JAVA, R. I. (1993). Recognising and remembering. In A. Collins, S. Gathercole, M. Conway, \& P. Morris (Eds.), Theories of memory (pp. 163-188). Hillsdale, NJ: Erlbaum.

Koriat, A., Ben-Zur, H., \& Nussbaum, A. (1990). Encoding information for future action: Memory for to-be-performed tasks versus memory for to-be-recalled tasks. Memory \& Cognition, 18, 568-578.

KVAVILASHVILI, L. (1987). Remembering intention as a distinct form of memory. British Journal of Psychology, 78, 507-518.

MAYLOR, E. A. (1990). Age and prospective memory. Quarterly Journal of Experimental Psychology: Human Experimental Psychology, 42, 471-491.

Morris, P. E. (1992). Prospective memory: Remembering to do things. In M. Gruneberg \& P. Morris (Eds.), Aspects of Memory (2nd ed.) (Vol. 1, pp. 196-222). London: Routledge.

Moscovitch, M. (1982). A neuropsychological approach to memory and perception. In F. I. M. Craik \& S. Trehub (Eds.), Aging and cognitive processes (pp. 55-78). New York: Plenum.

Nairne, J. S., Pusen, C., \& Widner, R. L., JR. (1985). Representation in the mental lexicon: Implications for theories of the generation effect. Memory \& Cognition, 13, 183-191.

NAIRNE, J. S., \& WIDNER, R. L., JR. (1988). Familiarity and lexicality as determinants of the generation effect. Journal of Experimental Psychology: Learning, Memory, \& Cognition, 14, 694-699.

Nilsson, L.-G., \& CraIK, F. I. M. (1990). Additive and interactive effects in memory for subject-performed tasks. European Journal of Cognitive Psychology, 2, 305-324.
Poon, L. W., \& Schaffer, G. (1982, September). Prospective memory in young and elderly adults. Paper presented to the American Psychological Association, Washington, DC.

ROEDIGER, H. L., III., \& MCDERMotT, K. B. (in press). Implicit memory in normal human subjects. In H. Spinnler \& F. Boller (Eds.), Handbook of neuropsychology (Vol. 8). Amsterdam; Elsevier.

WELFORD, A. T. (1958), Ageing and human skill. London: Oxford University Press.

WEST, R. L. (1984, August). An analysis of prospective everyday memory. Paper presented to the American Psychological Association, Toronto

West, R. L. (1988). Prospective memory and aging. In M. M. Gruneberg, P. E. Morris, \& R. N. Sykes (Eds.), Practical aspects of memory: Current research and issues (Vol. 2, pp. 119-125). Chichester, U.K.: Wiley.

Wilkins, A. J., \& BAdDeley, A. D. (1978). Remembering to recall in everyday life: An approach to absentmindedness. In M. M. Gruneberg, P. E. Morris, \& R. N. Sykes (Eds.), Practical aspects of memory (pp. 27-34). London: Academic Press.

\section{NOTES}

1. The details concerning order effects were as follows: for the main effect of order $\left[F(2,30)=1.55, M S_{\mathbf{c}}=4.30\right]$; for the interaction between order and task $\left[F(4,60)=1.19, M S_{e}=2.71\right]$; for the interaction between order and age $\left[F(2,30)<1, M S_{e}=4.30\right]$; for the interaction between order, task, and age $\left[F(4,60)<1, M S_{e}=2.71\right]$.

2. The details concerning order effects were as follows: for the main effect of order $\left[F(2,30)=1.14, M S_{\mathrm{c}}=0.04\right]$; for the interaction between order and task $\left[F(4,60)<1, M S_{\mathrm{e}}=0.01\right]$; for the interaction between order and age $\left[F(2,30)<1, M S_{\varepsilon}=0.04\right]$; for the interaction between order and list length $\left[F(2,30)<1, M S_{e}=0.01\right]$; for the interaction between order, task, and age $\left[F(4,60)<1, M S_{\mathrm{e}}=0.01\right]$; for the interaction between order, task, and list length $\left[F(4,60)<1, M S_{e}=\right.$ $0.01]$; for the interaction between order, age, and list length $[F(2,30)=$ $\left.2.21, M S_{e}=0.01\right]$; for the interaction between order, task, age, and list length $\left[F(4,60)=1.60, M S_{c}=0.01\right]$.

(Manuscript received October 15, 1992; revision accepted for publication May 12, 1993.) 